\title{
Study of Lipid Profile and Coronary Angiographic Pattern in Young Bangladeshi Patients with Acute Coronary Syndrome.
}

\author{
AR Khan ${ }^{1}$, AAS Majumder ${ }^{2}$ \\ ${ }^{1}$ Department of Cardiology, SSMC \& Mitford Hospital, ${ }^{2}$ Department of cardiology, NICVD
}

\begin{abstract}
:
Keywords: Lipid

profile, Coronary

Background: Majority of the patients of coronary heart disease (CHD) in our country are above 40 years of age but a good number of patients belong to the age under 40, the most valuable and productive period of life during which they can devote themselves to uplift their family, society and angiogram, Younger patients, Acute Coronary Syndrome. country and can participate in nation building activities. ${ }^{3,4}$ The number of young individuals falling into the spectrum of CHD is increasing everywhere However, this age trend is peculiar in relation to the western age incidence. ${ }^{5}$ Our objective was to investigate the lipid profile and coronary angiographic pattern in young Bangladeshi patients with acute coronary syndrome and also to find out the relationship between dyslipidemia and coronary artery disease in this age group.
\end{abstract}

Methods: This observational study was carried out in National Institute of Cardiovascular Diseases (NICVD) during the period of January 2000 to December 2000. A brief history was recorded on the date of admission and fasting lipid profile was done within 24 hours of admission. Other associated major risk factors were looked for and recorded accordingly. After stabilization oh the acute condition patient was prepared for coronary angiogram and informed consent was taken. Accordingly elective $C A G$ was done. Among them total 64 patients of ACS, underwent coronary angiogram in the cath lab of NICVD, were selected randomly of which of which 32 patients were up to the age 40 years (GroupI) and 32 were above 40 years of age (Group-II). Patient of ACS of either sex having no age limitation were included without prior history of Percutaneous Coronary Intervention or Coronary Artery Bypass Graft surgery. The findings were reviewed and scrutinized carefully by two interventional cardiologists. In doubtful cases third expert reviewed the CD. If a consensus was not reached due to technical or visual error, the case wais discarded from the study. Details of CAG findings i.e. site and number of diseased vessels, location, morphology and pattern of lesion were studied and recorded accordingly.

Results: The prevalence of dyslipidaemia and positive family history were more in group I than group II. Younger age group has less favorable lipid profile than older age group having raised total cholesterol in 31.3 percent cases, low HDL in 12.5 percent cases and raised LDL in 31.3 percent cases, while in older age group, it was 21.8, 25.0, 0 and 18.7 percent, respectively. CAG study of the patients showed that no vessel involvement was more common in group I than group II (21.9\% vs 12.5\%), but triple vessel disease was more common in group II (12.5\% vs 21.8\%). Single vessel and double vessel diseases were similar in both the groups. Involvement of LAD was slightly more in-group I than group II (68.8\% vs 65.6\%) and involvement of LCX and RCA were less in group I than group II (21.9\% vs $34.3 \%$, and $43.8 \%$ vs $78.1 \%$, respectively). Diffuse LAD and RCA lesions were more in group II ( $36.4 \%$ vs $52.4 \%$ and $42.9 \%$ vs $48.0 \%$, respectively), but diffuse LCX lesion was more in group I (42.9 vs $36.4 \%)$. Multiple irregular lesions are more common in older age group (53.1\%) than younger age group $(28.1 \%)$.

Conclusion: The younger age group has less favorable lipid profile than older age group having raised total cholesterol, decreased HDL and raised LDL. CAG findings show that most of the lesions are present in LAD (having less impressive LVEF) as like as in older age group, but older age group has more multiple irregular lesions. Prevalence of $\geq 2$ lesions in one coronary artery was more in group I (31 vs. 25\%) but difference was not statistically significant.

(Cardiovasc.j. 2009; 1(2) : 183-188)

\section{Introduction:}

Prior to world war II, acute myocardial infarction (AMI) was considered to be uncommon in patients under 40 years of age. The problem was brought into sharper focus in the post war years when Enos et al. published their pathological reports on 
coronary artery disease (CAD) in young soldiers killed in Korean conflict. ${ }^{1}$ During the past two decades AMI in patients under 40 years has been of increasing concern as evident by publications of Simson et al. and Davia et al. ${ }^{2}$

Because AMI may strike an individual during most productive years of life, it has profound deleterious psychological and economic ramifications. Majority of the patients of coronary heart disease (CHD) in our country are above 40 years of age but a good number of patients belong to the age under 40 , the most valuable and productive period of life during which they can devote themselves to uplift their family, society and country and can participate in nation building activities. ${ }^{3,4}$ The number of young individuals falling into the spectrum of CHD is increasing everywhere However, this age trend is peculiar in relation to the western age incidence. ${ }^{5}$

It is well known that smoking, hypertension, diabetes mellitus, family history and obesity are most important risk factors for CAD. The role (or association) of these risk factors in the pathogenesis of $\mathrm{CAD}$, whether equally important for both the younger and elderly patients, is still not yet convincingly established.

Risk factors of AMI in younger people ( $<40$ years) was observed in a study in our country, where smoking and high triglyceride were found to be strikingly associated risk factor for AMI in that group.

Elevated low density lipoprotein (LDL) cholesterol level is considered as a major cause of CHD. Numerous prospective epidemiological studies have identified a continuous, graded, direct relationship between serum total cholesterol level and CHD incidence. This relationship has been confirmed in many countries, in women, in elderly and in middle aged adults. Cholesterol level obtained in young adulthood predicts coronary disease decades later. Higher serum cholesterol level carry increased risk of $\mathrm{CAD}$ at younger ages. A higher incidence of lipid abnormality was found to exist in the younger patients of Heinl's series who found that 80 percent of 51 patients with an age range of 20 to 49 years had either type II or IV hyperlipoproteinaemia. ${ }^{6}$

Gofman et al. found that a hyperlipoproteinaemia in younger patients (aged 30 to 39 years) was more reliable as a predictive index of myocardial infarction than in older age group. In the discussion of a study done by Robert et al, it has been shown that particular striking feature was the enhanced frequency of lipoprotein abnormalities in younger subjects, amounting to 80 percent of those under age 50 with abnormal coronary artery. This is in line with other studies indicating a greater reliability of hypercholesterolaemia and hyperlipoproteinaemia as a predictive index of myocardial infarction in younger than in older male subjects. ${ }^{7,8}$ Such evidence supports the overwhelming need to identify younger patients with hyperlipoproteinaemia as one stop toward interventions aimed at the prophylaxis of accelerated CAD.

\section{Methodology:}

This observational study was carried out in National Institute of Cardiovascular Diseases (NICVD) during the period of January, 2000 to December 2000. A brief history was recorded on the date of admission and fasting lipid profile was done within 24 hours of admission. Other associated major risk factors were looked for and recorded accordingly. After stabilization of the acute condition patient was prepared for coronary angiogram and informed consent was taken. Accordingly elective CAG was done. Among them total 64 patients of ACS, underwent coronary angiogram in the cath lab of NICVD, were selected randomly of which of which 32 patients were up to the age 40 years (Group-I) and 32 were above 40 years of age (Group-II). Patient of ACS of either sex having no age limitation were included without prior history of Percutaneous Coronary Intervention or Coronary Artery Bypass Graft surgery. The findings were reviewed and scrutinized carefully by two interventional cardiologists. In doubtful cases third expert reviewed the CD. If a consensus was not reached due to technical or visual error, the case wais discarded from the study. Details of CAG findings i.e. site and number of diseased vessels, location, morphology and pattern of lesion were studied and recorded accordingly. All the relevant data was collected in a sheet and sent for appropriate statistical analysis.

\section{Results:}

Total 64 patients of ACS those who underwent subsequent $\mathrm{CAG}$ during the above-mentioned period 
were studied. It has been shown that mean age of group I and group II patients were 37.25 and 50.64 years, respectively, and all the patients are male (100\%) in group I, while 93.75 percent are male and 6.25 percent are female in group II. Chest pain was the most common presenting complains in both groups (93.8\% and $97.0 \%$, respectively). There was no significant difference in presenting complaints between the two groups $(\mathrm{P}>0.05)$.

\section{Table-I}

Clinical profile of study population $(n=64)$

\begin{tabular}{lccc}
\hline Parameters & Group-I $(\mathrm{n}=32)$ & Group-II(n=32) & $\mathrm{p}$ - value \\
\hline Age $(\mathrm{yrs})$ & $37.2(27-40)$ & $50.6(42-70)$ & 0.013 \\
Sex & & & 0.559 \\
$\quad$ Male & $32(100 \%)$ & $30(93.8 \%)$ & \\
$\quad$ Female & $0(0 \%)$ & $02(6.2 \%)$ & \\
Chest pain & $30(93.8 \%)$ & $31(97.0 \%)$ & 0.559 \\
Dyspnoea & $12(37.5 \%)$ & $14(43.7 \%)$ & 0.681 \\
Sweating & $24(75.0 \%)$ & $24(75.0 \%)$ & 0.956 \\
\hline
\end{tabular}

Smoking was found to be most common risk factor in both groups ( $84.4 \%$ and $75.0 \%$, respectively), while it was slightly more in group I than group II, but difference was not significantly associated. But there was significant difference $(\mathrm{P}=0.015$, i.e. $<0.05)$ in the prevalence of dyslipidaemia between the two groups $(56.3 \%$ in group I and $28.1 \%$ in group II). Diabetes was found to be less in group I than group II (12.5\% vs. $21.8 \%$, respectively), whereas family history was more positive in group I than group II ( $34.4 \%$ vs. $25.0 \%$, respectively), but differences were not significant regarding both the variables between the two groups. Also there was no significant difference in the prevalence of hypertension between the two groups (46.9\% in group I and $43.7 \%$ in group II). The mean number of major clinical risk factors were $2.34 \pm 1.10$ in group I and $1.90 \pm 0.91$ in group II. Though it is more in-group I than in-group II, but difference was not statistically significant.

\section{Table II}

Distribution of major clinical risk factors profile among the study population ( $n=64)$

\begin{tabular}{lccc}
\hline Risk factors & $\begin{array}{c}\text { Group I } \\
(\mathrm{n}=32)\end{array}$ & $\begin{array}{c}\text { Group II } \\
(\mathrm{n}=32)\end{array}$ & p-value \\
\hline Smoking & $27(84.4 \%)$ & $24(75.0 \%)$ & 0.352 \\
HTN & $15(46.9 \%)$ & $14(43.7 \%)$ & 0.751 \\
Dyslipidaemia & $18(56.3 \%)$ & $09(28.1 \%)$ & 0.015 \\
Diabetes & $4(12.5 \%)$ & $7(21.8 \%)$ & 0.269 \\
Family history & $11(34.4 \%)$ & $8(25.0 \%)$ & 0.368 \\
\hline
\end{tabular}

\section{Table III}

Number of major clinical risk factors $(n=64)$

\begin{tabular}{|c|c|c|c|}
\hline $\begin{array}{l}\text { Number of } \\
\text { Risk Factors }\end{array}$ & $\begin{array}{l}\text { Group-I } \\
(\mathrm{n}=32)\end{array}$ & $\begin{array}{c}\text { Group- II } \\
(\mathrm{n}=32)\end{array}$ & $\overline{P \text {-value }}$ \\
\hline None & $1(3.1 \%)$ & $1(3.1 \%)$ & 0.249 \\
\hline Single & $8(25.0 \%)$ & $9(28.1 \%)$ & \\
\hline Two & $6(18.8 \%)$ & $12(37.5 \%)$ & \\
\hline More than two & $17(53.1 \%)$ & $10(31.2 \%)$ & \\
\hline
\end{tabular}

Lipid profile study showed that Group I had more dyslipidaemia than group II patients which is statistically significant Group I had less favorable lipid profile, i.e. higher triglyceride level and lower HDL level in group I, than group II, but the difference was not statistically significant between the two groups.

Table-IV

Lipid profile of the study population $(n=64)$

\begin{tabular}{|c|c|c|c|}
\hline Lipid profile & $\begin{array}{l}\text { Group I } \\
(\mathrm{n}=32)\end{array}$ & $\begin{array}{c}\text { Group- II } \\
(\mathrm{n}=32)\end{array}$ & $\overline{p \text {-value }}$ \\
\hline $\begin{array}{l}\text { Total cholesterol } \\
(\mathrm{mg} / \mathrm{dl})\end{array}$ & $216.5 \pm 52.8$ & $201.0 \pm 35.0$ & 0.087 \\
\hline $\begin{array}{l}\text { Triglyceride } \\
(\mathrm{mg} / \mathrm{dl})\end{array}$ & $231.8 \pm 69.5$ & $204.6 \pm 54.0$ & 0.056 \\
\hline $\mathrm{HDL}(\mathrm{mg} / \mathrm{dl})$ & $38.4 \pm 4.4$ & $40.5 \pm 13.2$ & 0.485 \\
\hline$\underline{\mathrm{LDL}}(\mathrm{mg} / \mathrm{dl})$ & $127.7 \pm 15.6$ & $126.8 \pm 17.6$ & 1 \\
\hline \multicolumn{4}{|c|}{$\begin{array}{c}\text { Table-V } \\
\text { Nature of dyslipidaemia among the study } \\
\text { population }(n=64)\end{array}$} \\
\hline$\overline{\text { Lipids }}$ & $\begin{array}{l}\text { Group I } \\
(\mathrm{n}=32)\end{array}$ & $\begin{array}{c}\text { Group- II } \\
(\mathrm{n}=32)\end{array}$ & $\overline{p \text {-value }}$ \\
\hline $\begin{array}{l}\text { Total Cholesterol } \\
(\geq 200 \mathrm{mg} / \mathrm{dl})\end{array}$ & $10(31.3 \%)$ & $7(21.8 \%)$ & 0.356 \\
\hline $\begin{array}{l}\text { Triglyceride } \\
(\geq 200 \mathrm{mg} / \mathrm{dl})\end{array}$ & $12(37.5 \%)$ & $8(25.0 \%)$ & 0.24 \\
\hline $\mathrm{HDL}(\leq 35 \mathrm{mg} / \mathrm{dl})$ & $4(12.5 \%)$ & $1(3.1 \%)$ & 0.198 \\
\hline $\mathrm{LDL}(\geq 130 \mathrm{mg} / \mathrm{dl})$ & $10(31.6 \%)$ & $6(18.7 \%)$ & 0.215 \\
\hline
\end{tabular}

CAG study of the patients showed that no vessel involvement was more common in group I than group II (21.9\% vs $12.5 \%)$, but triple vessel disease was more common in group II (12.5\% vs $21.8 \%)$. Single vessel and double vessel diseases were similar in both the groups. Involvement of LAD 
was slightly more in-group I than group II (68.8\% vs $65.6 \%$ ) and involvement of LCx and RCA were less in group I than group II (21.9 vs 34.3 and 43.8 vs $78.1 \%$, respectively). Diffuse LAD and RCA lesions were more in group II (36.4\% vs $52.4 \%$ and $42.9 \%$ vs $48.0 \%$, respectively), but diffuse LCx lesion was more in group I (42.9\% vs $36.4 \%)$. Multiple irregular lesions are more common in older age group (53.1\%) than younger age group (28.1\%).

Table-VI

Severity of coronary artery disease among the study population $(n=64)$

\begin{tabular}{lccc}
\hline Parameters & $\begin{array}{c}\text { Group I } \\
(\mathrm{n}=32)\end{array}$ & $\begin{array}{c}\text { Group- II } \\
(\mathrm{n}=32)\end{array}$ & $\mathrm{p}$-value \\
\hline $\begin{array}{l}\text { Single vessel } \\
\text { disease }\end{array}$ & $11(34.4 \%)$ & $10(31.2 \%)$ & 0.532 \\
$\begin{array}{l}\text { Double vessel } \\
\text { disease }\end{array}$ & $10(31.3 \%)$ & $11(34.3 \%)$ & \\
$\begin{array}{l}\text { Triple vessel } \\
\text { disease }\end{array}$ & $4(12.5 \%)$ & $7(21.8 \%)$ & \\
No vessel disease & $7(21.9 \%)$ & $4(12.5 \%)$ & \\
\hline
\end{tabular}

Table VII

Individual vessel involvement among the patient population $(n=64)$

\begin{tabular}{lccc}
\hline Coronary artery & $\begin{array}{c}\text { Group I } \\
(\mathrm{n}=32)\end{array}$ & $\begin{array}{c}\text { Group- II } \\
(\mathrm{n}=32)\end{array}$ & $\mathrm{p}$-value \\
\hline Left main & $1(3.1 \%)$ & $1(3.1 \%)$ & 0.747 \\
$\begin{array}{l}\text { Left anterior } \\
\text { descending artery } \\
\text { (LAD) }\end{array}$ & $22(68.8 \%)$ & $21(65.6 \%)$ & 0.943 \\
$\begin{array}{l}\text { Left circumflex } \\
\text { artery (LCX) }\end{array}$ & $7(21.9 \%)$ & $11(34.3 \%)$ & 0.175 \\
$\begin{array}{l}\text { Right coronary } \\
\text { artery (RCA) }\end{array}$ & $14(43.8 \%)$ & $25(78.1 \%)$ & 0.105 \\
\hline
\end{tabular}

Table-VIII

Morphological types of lesions among the study population $(n=64)$

\begin{tabular}{lccc}
\hline Type of lesions & $\begin{array}{c}\text { Group I } \\
(\mathrm{n}=32)\end{array}$ & $\begin{array}{c}\text { Group- II } \\
(\mathrm{n}=32)\end{array}$ & $\mathrm{p}$-value \\
\hline Concentric & $24(75.0 \%)$ & $30(93.7 \%)$ & 0.072 \\
Eccentric & $6(18.7 \%)$ & $2(6.2 \%)$ & 0.201 \\
Multiple & $9(28.1 \%)$ & $17(53.1 \%)$ & 0.032 \\
irregularities & & & \\
Totally occluded & $4(12.5 \%)$ & $1(3.1 \%)$ & 0.256 \\
\hline
\end{tabular}

Table-IX

Diffuse coronary artery lesions among the study population $(n=64)$

\begin{tabular}{lcc}
\hline $\begin{array}{l}\text { Diffusely involved } \\
\text { vessels }\end{array}$ & $\begin{array}{c}\text { Group I } \\
(\mathrm{n}=32)\end{array}$ & $\begin{array}{c}\text { Group- II } \\
(\mathrm{n}=32)\end{array}$ \\
\hline $\begin{array}{l}\text { Total no of diffuse } \\
\text { lesions }\end{array}$ & $17(39.5 \%)$ & $27(46.5 \%)$ \\
$\begin{array}{l}\text { Diffusely LAD to } \\
\text { no. of LAD lesions }\end{array}$ & $8 / 22(36.36 \%)$ & $11 / 21(52.3 \%)$ \\
$\begin{array}{l}\text { Diffusely LCX to } \\
\text { no. of LCX lesions }\end{array}$ & $3 / 7(42.85 \%)$ & $4 / 11(36.36 \%)$ \\
$\begin{array}{l}\text { Diffusely RCA to } \\
\text { no. of RCA lesions }\end{array}$ & $6 / 14(42.85 \%)$ & $12 / 25(48.0 \%)$ \\
\hline
\end{tabular}

\section{Discussion:}

While there are several studies from developed countries on risk factor analysis and angiographic profile in younger patients with coronary heart disease (CHD) like myocardial infarction and unstable angina, such studies are quite scanty in our country. ${ }^{9}$

This study was intended to evaluate the lipid profile $\&$ angiographic pattern of Acute Coronary Syndrome in younger Bangladeshi patients. This study observed marked difference in the prevalence of major and minor clinical risk factors in younger patients in comparison to older age group. There is also a little difference in the angiographic appearance in patients with myocardial infarction and unstable angina of the two groups. It is to be mentioned here that CHD in younger female is much less than male. The lower female percentage may be due to social customs that restrict women seeking medical help outside the home even in face of serious illness. In younger age group, low percentage of female patients may be due to the fact that they are partially immune to IHD during their reproductive life. Elevated LDL cholesterol is considered as a major cause of IHD. Cholesterol level obtained in young adulthood predict coronary disease decades later. ${ }^{10} \mathrm{~A}$ higher incidence of lipid abnormality was found to exist in the younger patients of Heinl's series who found that 80 percent of 51 patients with an age range of 20 to 49 years had either type II or IV hyperlipoproteinaemia. ${ }^{6}$ Gofman et al. (1966) found that a hyperlipoproteinaemia in younger patients was more reliable as a predictive index of myocardial infarction than in older age group. The incidence of hypercholesterolaemia 
was higher (15.2\%) in younger age group than older age group (7.3\%) and the difference was significant. This study also showed the higher prevalence of dyslipidaemia in younger age group than older age group (56.3\% vs $28.1 \%$ ) and the difference was statistically significant. This is in line with the other studies indicating a greater reliability of hypercholesterolaemia and hyperlipoproteinaemia as a predictive index of myocardial infarction in younger than in older subjects. ${ }^{7}{ }^{11}$ Such evidence supports the overwhelming need to identify younger patients with hyperlipoproteinaemia as one step towards intervention aimed at the prophylaxis of accelerated CAD. The mean number of major clinical risk factors was $2.34 \pm 1.10$ in younger age group and $1.90 \pm 0.91$ in older age group. The presence of multiple conventional risk factors appeared to be more common in younger patients with myocardial infarction. Only one patient was free from all of the accepted major clinical risk factors in both age group. In this study, 53.1 percent young patients had more than two major risk factors while in older age group 31.2 percent had more than two risk factors. This finding closely resembles with the study by Islam. ${ }^{9}$ These observations agree with the view that young infarction patients had three or more risk factors, while most of the older patients had only one or two risk factors. ${ }^{9}$

In younger age group, 12.5 percent had raised blood sugar (random) and 56.3 percent had dyslipidaemic lipid level while in older age group the values were $25 \%$ and 28.1 percent, respectively. The mean value of total cholesterol, triglyceride, HDL and LDL were $216.53 \pm 52.81,231.78 \pm 69.53,38.37 \pm 4.41$ and $127.71 \pm 15.65 \mathrm{mg} / \mathrm{dl}$, respectively, in younger age group, while it were 201.00 \pm 35.00 , $204.60 \pm 54.00,40.51 \pm 13.24$ and $126.80 \pm 17.60 \mathrm{mg} /$ $\mathrm{dl}$, respectively, in older age group. In younger age group, 31.3 percent had raised total cholesterol, 37.5 percent had raised triglyceride, 12.5 percent had lower HDL and 31.3 percent had raised LDL level. These values in older age group were 21.8, 25.0, 3.1 and 18.7 percent, respectively. Though the difference between the two groups is not significant, but younger age group had less favourable lipid profile, which is in line with other studies. ${ }^{6,7,11}$ CAG findings show that the most commonly affected vessel in our study was the LAD (68.75\%), followed by RCA (43.8\%) and LCx (21.9\%) in younger age group, while in older age group it was 65.6, 78.1 and 34.3 percent, respectively. LAD involvement is slightly higher in precocious group while involvement of RCA is strikingly higher in older age group in comparison to precocious group. In the study of Davia et al., LAD artery was involved in 60 percent of the patients. The RCA and $\mathrm{LCx}$ arteries were involved in 57.5 and 45 percent, respectively. Both the above studies parallel the findings of the Cleveland Clinic Group in the young patients. ${ }^{2,12}$ In both the groups, only one patient had left main lesion. We found single vessel disease in 34.4 percent of our patients in younger age group, double vessel disease in 31.3 percent and triple vessel disease in 12.5 percent cases, whereas in older age group, the values were $31.2,34.3$ and 21.84 percent, respectively. In younger age group, 7 patients $(21.9 \%)$ had no vessel involvement while in older age group it was 4 (12.5\%). Davia et al. found that 60 percent of their patients under 40 years of age had single vessel disease, while Welch found single vessel disease in 36 percent of their patients under 40 years of age. ${ }^{3,12}$ The findings of this study parallels the above two studies. Our findings of fewer diseased arteries per patient and a greater frequency of single vessel disease is probably a reflection of a younger age group in whom it would be expected that the disease would be less far advanced. Proximal lesion in LAD and middle segment lesion in LCx and RCA are more common in younger age group, the comparative values are 68.2 vs 61.9 percent, 85.7 vs 54.7 percent and 50 vs 28 percent, respectively. From this study, we can say that the lesions are more nearer to the origin of the individual coronary artery. Other authors have stated that IHD in younger age group under 40 is different and is more localized arterial disease and the factor of importance is, therefore, not the nature but the distribution of the vessel's lesions.

Regarding pattern of lesion, 63.6 percent was discrete and 36.4 percent were diffuse in LAD, likewise, 57.1 and 42.9 percent were in LCX, and 57.1 and 42.9 percent were in RCA, discrete and diffuse respectively. On the contrary, pattern of lesion in older age group was that discrete lesions were 47.6, 63.3 and 52.0 percent in LAD, LCX and RCA, respectively, whereas diffuse lesions were 52.4, 36.4 and 48.0 percent in LAD, LCX and RCA, respectively.

Total number of diffuse lesions were 17 (39.53\%) in younger age group, while in older age group, it was $27(46.5 \%)$. The figures in two groups are 
more or less similar but number of diffuse LAD to number of LAD lesions was more in older age group (8/22 vs 11/21). Accordingly, diffuse LCX to number of LCX lesions and diffuse RCA to number of RCA lesions in group I and group II were $3 / 7$ vs $4 / 11$ and $6 / 14$ vs $12 / 25$, respectively. Regarding morphology of the lesions, four types of lesions were recorded: concentric, eccentric, multiple irregularities and totally occluded. The incidence of different morphological types of lesions were $75.0,18.7,28.1$ and 12.5 percent, respectively, in younger age group, while in older age group, it were 100.0, 6.2, 53.1 and 3.1 percent, respectively. Multiple irregular lesions are obviously more prevalent in older age group.

Most of the lesions found in both the groups were significant, i.e. within $7099 \%$, having the prevalence of 69.09 percent in younger age group and 68.33 percent in older age group. Only 4 lesions (7.27\%) in younger group and 2 lesions (3.33\%) in older age group had 100 percent occlusion. Majority of the significant lesions were in LAD in both the groups (32.72 vs. 30\%), followed by RCA (21.81 vs. $26.66 \%$ ) and LCX (12.72 vs $11.66 \%$ ).

Regarding number of lesions in each coronary artery in group I, 59.4 percent had single lesion and 9.4 percent had $\geq 2$ lesions in LAD, likewise, 15.6 and 6.3 percent in LCX and 28.1 and 15.6 percent in RCA, respectively. On the other hand, in group II, it were 53.1 and 12.5 percent, 37.5 and 0 percent, and 62.5 and 12.5 percent in LAD, LCX and RCA, respectively. Prevalence of single lesion was more frequent in both the groups but the prevalence of $\geq 2$ lesions in one coronary artery was mildly more in-group I than group II ( $31 \%$ vs. $25 \%)$.

This study was done with small study population and accuracy of lipid profile measurement was avid questionable.

\section{Study limitations:}

The study was carried out in a single centre with small sample volume. So the conclusion of the study should not be considered absolute and further multicentre study with large sample volume is needed.

\section{Conclusion:}

At present time, ACS in young adult are one of the major challenges faced by cardiologists. Control of certain risk factors for CHD is associated with decrease in mortality and morbidity from myocardial infarction and unstable angina. So, identification and taking appropriate measures for primary and secondary prevention of such risk factors is, therefore, of great importance. The study of coronary artery lesions in younger age group by CAG will reveal the disease process thereby it will be helpful for taking decision regarding proper management. From this study we conclude that the younger age group has less favorable lipid profile than older age group having raised total cholesterol, decreased HDL and raised LDL.CAG findings show that most of the lesions are present in LAD (having less impressive LVEF) as like as in older age group, but older age group has more multiple irregular lesions. Prevalence of $\geq 2$ lesions in one coronary artery was more in group I (31 vs. 25\%) but difference was not statistically significant.

\section{Referrences:}

1. Enos WF Jr, Beyer JC, Holmes RH. Pathogenesis of coronary disease in American soldiers killed in Korea. JAMA 1955; 158:912 4

2. Davia JE, Haltal FJ, Cheitlin MD, Gregoratos G, McCarty R, Foote W. Coronary artery disease in young patients: Arteriographic and clinical review of 40 cases aged 35 and under. Am Heart $J$ 1974; 87:689 96.

3. Khandaker RK, Hossain D, Hossain M, Shamsuzzaman. Retrospective analysis of acute myocardial infarction: A 4 years study of 2690 patients. Bangladesh Heart $J$ 1987; 1:14 7 .

4. Malik A. Congenital and acquired heart diseases: A survey of 7062 persons. Bangladesh Med Res Coun Bull 1976; 11:115 9.

5. McKeigue PM. Coronary heart disease in Indians, Pakistanis, and Bangladeshis: Aetiology and possibilities of prevention [editorial]. Br Heart J 1992; 67:341 2.

6. Crawford T, Dexter D. Coronary artery pathology in sudden death from myocardial ischaemia: A comparison by age groups. Lancet 1961;i:181 5 .

7. Kannel WB, McGee DL. Diabetes and cardiovascular disease: The Framingham study. JAMA 1979; 241:2036 8.

8. Rapaport E, Bilheimer DW, Chobanian AV, Hajjar DP, Hawkins CM, Hutchins GM, et al. [NIH Consensus Development Panel on Triglyceride, High Density Lipoprotein, and Coronary Heart Disease]. Triglyceride, high density lipoprotein, and coronary heart disease. JAMA 1993; 269:505 10.

9. Islam MF. Acute myocardial infarction in young adults: (Risk factors and early prognosis) a comparative clinical study with elderly patients [thesis]. University of Dhaka, Dhaka. 1989.

10. Maron DJ, Ridker PM, Pearson TA. Risk factors and the prevention of coronary heart disease. In: Alexander RW, Schlant RC, Fuster V (eds). Hurst's the Heart, 9th ed. New York, McGraw Hill Book Inc. 1998:1175 95.

11. Gofman JW, Young W, Tandy R. Ischemic heart disease, atherosclerosis, and longevity. Circulation 1966; 34:679 97.

12. Welch JE. Coronary arteriography in young man. Circulation 1970; 42:1970. 